EMERGING VOICES

\title{
The Representation of Male Leads in Selected Animated Films: A Visual Analysis
}

\author{
Sarah Shehattah*
}

\section{Introduction}

The genre of animation has attracted academic attention due to its growing popularity and success as an entertainment and aesthetic genre. Hapkiewicz (1979) pointed out that animation productions are very popular among children aged between 18 months and two years. Therefore, they could influence children's perceptions, behavior and attitudes at a very young age. Animation films and television cartoons can deliver certain messages to children whether explicitly or implicitly. Such messages can be useful and educational (Baranova, 2014; Padilla-Walker, Coyne, Fraser, \& Stockdale, 2013) or harmful and distorted (Coye \&Whitehead, 2008; Indhumathi, 2019; Klein \& Shiffman, 2006, 2008). Not only children, but also young adults have shown interest in animated films and have been influenced by the messages they contained (Barnes, 2012; Bruce, 2007; Hayes \&Tantleff-Dunn, 2010). In fact, animation studios, Disney for example, managed to transform a "child-oriented genre" into a "massoriented" entertainment that implicitly depicts power relations and sexuality (Zarranz, 2007, p. 55).

Gender portrayal and representations of gender roles in animation production have been investigated by many scholars. Depictions of gender stereotypes in animated films (Coyne, Lindner, Rasmussen, Nelson, \& Birkbeck, 2016; Seybold \& Rondolino, 2018; Smith, Pieper, Granados, \& Choueiti, 2010 ) and in television animated cartoons (e.g., Ahmed \& Abdul Wahab, 2014; Coyne, Linder, Rasmussen, Nelson, \& Collier, 2014; Leaper, Breed, Hoffman, \& Perlman, 2002; Thompson \& Zerbinos, 1995, 1997) have received considerable attention from researchers and analysts. Overrepresentation of male characters

\footnotetext{
* Assistant Lecturer in the English Department, Faculty of Foreign Languages and Translation, Misr University for Science \& Technology (MUST), Egypt. This paper is derived from a Ph.D. thesis in progress entitled "Gender Representation in Selected American Animation Movies: A Pragmatic and Multimodal Analysis" (Cairo University), supervised by Prof. Ola Hafez, Prof. Amani Badawy, Dr. Eenas Metwally. Cairo Studies in English 2020(1): https://cse.journals.ekb.eg/
} 
and depicting them as physically forceful leaders and superheroes (Baker \& Raney, 2007) in contrast to the underrepresentation of female characters that frequently demonstrated passivity, affection and interest in physical appearance (e.g., Bazzini, Curtin, Joslin, Regan, \& Martz, 2010; Elnahla, 2015; Fischer, 2010) were all negative messages of gender favoritism. Studies have shown that exposure to these gendered messages can influence viewers' gender perceptions, preferences and social behaviors (Gökçearslan, 2010; Holub, Tisak, \& Mullins, 2008).

According to sociology theorists, children acquire the stereotypical gender roles through multiple ways. Based on the social learning theory, children learn through observation of everything they are exposed to (Condry, 1984). They observe members of their own sex in order to learn their expected attitudes and behavior (Peirce, 1989). For example, boys seem attracted to masculine role models and imitate their behavior (Hoffner, 1996; Slaby \& Frey, 1975). Furthermore, heavy viewers of superhero television shows, especially preschool boys, tend to adopt male-stereotyped toy play and more weapon play (Coyne et al., 2014). These boys' play practices reflect the gendered behaviors they observe and copy from the animated role models on television and in movies (Bussey \& Bandura, 1999, as cited in Ward \& Aubrey, 2017).

Gender identities, i.e., masculinity and femininity, are defined as collections of physical, mental, emotional, and social traits that shape certain social expectations for the roles of people in the community (Carrigan, Connell, \& Lee, 1985). Connell (2005) argued that gender identity should be represented as "the processes and relationships through which men and women conduct gendered lives" and "the effects of these practices in bodily experience, personality, and culture" (p. 71). This is pertinent to the creation and portrayal of animated characters in films and television. As Birthisel (2014) stated, animators start a character with a sketch of a body that is associated with gender-related concepts, traits and actions throughout the animation storyline.

The notion of essential identities has been criticized and resisted by social constructionists. They have argued that gender identity is "the result of affiliation to particular beliefs and possibilities which are available" to individuals "in their social context" (Ivanic, 1998, p.12). The notion and study of the multiplicity of gender identities have grown: different femininities and masculinities, evident across populations and cultural contexts, and also within individuals. The plural word 'identities' is considered accurate in capturing how people identify simultaneously with a variety of social groups. Ivanic (1998) explained how people's diverse identities constitute their rich sense of self. In addition, Bem (1974) implied that men and women possess both masculine and feminine 
qualities. Bem (1974) also argued that having both masculine and feminine personal traits, which is referred to as being psychological androgynous, was optimal for psychological adjustment. This research paved the way for subsequent revolutionary research on gender identity over the following years (Marecek et al. 2003).

Due to their growing success and popularity among youngsters and even adults, animated films have offered rich data for analysis. Scholars and analysts have applied multiple approaches to analyze animated films including content analysis (e.g., Decker, 2010; England, Descartes, \& Collier-Meek, 2011; Fischer, 2010), critical analysis (e.g., Pimentel \& Velázquez, 2008; Wormer \& Juby, 2016), (post-) feminist analytical approaches (e.g., Macaluso, 2018), thematic analysis (e.g., Patterson \& Spencer, 2017) and gender role theory (e.g., Putri, 2017), offering significant findings about representations of gender roles and stereotypes in animated cartoons. However, insufficient attention has been given to applying visual analysis of gender depictions in animations as a visual medium.

In fact, Mills (1995) stressed that "analysis of images and texts representing gender difference enables us to trace the options available to subjects in terms of the construction of subject positions or roles" (p.2). For example, a social semiotic visual analysis could highlight the nonverbal messages that are visually depicted in animated films; for example, how female and/or male characters are visually portrayed on screen and how their portrayals contribute to the construction of gender roles in the viewers' minds. This is very much connected to the concept of socialization originated by Ochs (1988), through which she explained how individuals in a community acquired certain sociocultural knowledge and practices in order to become eligible members of their community. Consequently, conducting a visual analysis of animated films can yield significant insights about the representation of gender roles and practices that might influence the perceptions and attitudes of viewers.

This paper aims to explore the visual depiction of male protagonists in three animated films, namely Despicable Me II (2013), How to Train your Dragon II (2014) and Big Hiro 6 (2014). These films are enlisted as the highest grossing animated films with human male leading characters produced in the years 20132014. This study aims to answer one main question: How are the three male protagonists' gender (roles) identities constructed visually through represented narrative processes and participant roles? 


\section{Literature review}

Studies of gender representation in animation production have varied. Besides research on sexism and gender stereotyping in animated films (Bazzini et al., 2010; Coyne et al., 2016; Laemle, 2018; Letaief , 2015; Smith et al., 2010), several studies reported the development in the representation of gender roles in animated films (England et al., 2011; Fischer, 2010; and Wiersma, 2000). Wiersma (2000), for instance, examined gender representation in sixteen Disney full-length feature films spanning from 1937 to 1997, applying a qualitative content analysis and a social construction framework. Findings indicated that female and male characters did not represent traditional feminine and masculine traits respectively, especially in the most recent productions. That is, some male characters were portrayed dependent and romantic whereas female characters were rendered as independent. These findings reflected Disney's early steps towards the development of gender representations and breaking gender stereotypes.

Moreover, Fischer (2010) conducted quantitative content analysis to examine the distribution and portrayal of female and male characters in a selection of five animated films in the period from 2004 to 2008. The findings revealed some progress toward positive representations through reducing stereotypes of female and male characters. The female characters were rendered in diverse roles and less stereotypical images as beautiful, in leadership roles, in careers, as angry, dominant, independent, and intelligent. Conversely, the male characters were represented in different roles including followers, leaders, and heroes; and with non-stereotypical characteristics such as scared, caring/loving, fearful and dependent. These findings indicated how stereotypical gender images still occur in animated movies; however, they have progressed positively by promoting less traditional images of females and males.

Furthermore, England et al. (2011) investigated portrayal of the prince's and princess' characters, i.e., their behavioral characteristics and climactic outcomes, in nine selected Disney films. Content coding analyses revealed how Disney's early productions (i.e., Snow White, Cinderella, and Sleeping Beauty) exhibit stereotypical gender traits of princes (e.g., brave, physically strong and assertive) and princesses (e.g., helpful, affectionate and fearful). Disney's 1980s and 1990s productions (e.g., Aladdin and Mulan) reflect how princes' and princesses' characters developed to be more complex than earlier ones. For example, princesses became assertive and career-oriented participating in traditionally masculine activities such as war. Also, princes became complex and showed some traditionally feminine traits, e.g., incompetence and naivety. In fact, England et al. (2011) underlined how princes and princesses were characterized 
by both masculine and feminine qualities which demonstrated their complexity and development over time. For example, princesses represented independence and assertiveness together with affection and fearfulness. Similarly, princes were depicted as both physically weak but brave, and athletic but fearful. This is how a more balanced gender depiction is offered through recent Disney productions.

Other analysts have given great attention to investigating the representation of female characters in animation films, particularly in Disney films. These include Zarranz (2007), Sumera (2008), Davis (2014), Ebrahim (2014), Lueke (2014) and Toth (2017) that have revealed the development in the portrayal of many of Disney heroines. Conversely, few researchers have explored the portrayal of males and masculinity in animation film productions. Examples of these include Jeffords (1995), Gillam and Wooden (2008), Finklea (2014), Davis (2015) and Macaluso (2018). Jeffords' (1995) study was one of the earliest attempts to examine the representation of males and masculinity in the 1990s. She focused on male portrayal as "sensitive new man" (p.170) in Disney's Beauty and the Beast. Jeffords pointed out that the Beast's role manifests a major transformation in the male leading character from "the hardened, muscle-bound, domineering man of the ' 80 s into the considerate, loving and self-sacrificing man of the '90s" (p.170). As Jeffords argued, the Beast's story implies that "masculinity has been betrayed by its own cultural imagery: what men thought they were supposed to be-strong protective, powerful, commanding-has somehow backfired and become their own evil curse" (p.171). Although the Beast is characterized as strong, protective, imposing, domineering, and overpowering, he is represented as childish, petulant, and needing to learn to love and be sensitive.

Such portrayal of males with mixed features of masculinity and femininity was also underlined through Gillam and Wooden's (2008) analysis of portrayals of masculinity in Pixar animation productions. They noted a shift in the representation of males from alpha males who were characterized by strength, independence and assertiveness into beta males that had feminine traits, such as vulnerability, altruism and affection, besides their masculine qualities. This portrayal has offered a new understanding of manhood or the so-called "new male" that involves males' acceptance of their "feminine aspects" (Gillam $\&$ Wooden, 2008, p.2). The new male image combines both masculine features such as bravery and intelligence and feminine features such as caring, nurturing and bonding with others.

Furthermore, Finklea (2014) adopted a qualitative thematic approach to examine the representation of masculinities in Pixar's first 13 feature-length animated films. Findings revealed six major themes about masculinities. These 
include portrayals of successful males who take part in teamwork; males who are naturally brave and have heterosexual desires; male parents who are fearful about the future, and male bosses who are predominantly greedy. The analysis also highlighted the depicted journey of male characters toward becoming new men who can express their romantic emotions. Finklea concluded that Pixar's films mirrored societal shifts in masculinities during the 1990s and 2000s, including crises of masculine portrayal, identity and leadership.

Providing a broader and more detailed analysis, Davis (2015) attempted to categorize male characters presented in Disney animated films. She pinpointed three broad categories of males: the dashing hero, the handsome prince, and the evil villain. The dashing hero is usually represented by a boy or a young man who grows into a mature man through gaining knowledge and experience, the handsome prince exhibits bravery through rescuing the princess, and finally the villain represents the hegemonic masculinity model of dominating males. Macaluso (2018) added a fourth category, namely the post-feminist hero, who possesses features of both "hegemonic masculinity and the effeminate or absence of masculinity" (p.4). Examining several characters in the Disney films, The Incredibles, Macaluso argued that these films were promoting a new model of postfeminist masculinity.

In addition, Putri (2017) adopted the gender role theory by John Money (1955) to investigate Pixar's gender role ideology and representation of masculinity in two animated films, namely Wall-E and Monsters University. According to this theoretical model, feminine traits include supportive, passive, timid, emotional, cautious and nurturing. On the other hand, masculine traits include dominant or seeking social dominance, aggressive, bold, rational, prone to take risks, reckless, protective, and strong (Cited in Putri, 2017). Findings indicated that both films promote the ideology that masculine gender role traits are put in higher hierarchy. Putri argued that the communities depicted in the two films value the traits of being logic-oriented, strong, socially dominant, aggressive and reckless. These are considered masculine traits (Schmitt, Voracek, Realo, \& Allik, 2008) that make male characters successful (Putri, 2017). Nonetheless, portrayals of male protagonists in the two films debunk such ideology and suggest that adopting both masculine and feminine traits can enable male protagonists to be successful. In fact, male leads demonstrate and develop certain feminine traits, such as sentimentality, intimidation, physical weakness, and supportiveness which bring about positive results for the two male leads. Accordingly, it has been concluded that Pixar animation studios seem to support androgyny as both feminine and masculine traits intertwine together through the representations of male leads. 
Generally, these studies have exemplified the major interest in Disney's and Pixar's animated production whereas other animation studios productions have been overlooked, e.g., DreamWorks and Illumination Entertainment. Also, heavy reliance on content and thematic analyses of animated films seems evident while insufficient attention has been given to the scrutiny of visual depiction of masculinity and male representation in animated films despite its potential contribution to the understanding of gender portrayal in animation films as a visual medium. To my knowledge, the selection of films under study has not been examined from a visual perspective. This gap in the literature is what my study aims to fill by contributing to the existing body of research on gender, animation and visual analysis.

\section{Methodology}

\subsection{Sample}

A social semiotic visual analysis (Kress \&van Leeuwen, 2006) was conducted on three selected feature-length animated movies. Using purposive sampling, movies produced by different animation studios were selected that have the highest box-office gross in the period 2013-2014 according to the Box Office revenues (Box Office Mojo, 2019). The films were chosen based on featuring human male leading characters. These films are Despicable Me II (June, 2013), How to Train your Dragon II (June, 2014), and Big Hero 6 (October, 2014). The total duration of the three films is five hours, three minutes and five seconds. The plots of the three selected animated films are as follows:

- Despicable Me 2 (2013) is the sequel to the computer-animated comedy Despicable Me (2010) in which the male protagonist, Gru, has been represented as a supervillain who despite his evil supremacy, manages to change into a caring and loving adoptive parent to three little orphan girls and decides to give up villainy. The sequel depicts Gru trying to help the Anti-Villain League (AVL), with a female assistant agent, Lucy Wilde, to track down "El Macho", a legendary supervillain. Eventually, they both succeed in their mission and they get married.

- How to Train Your Dragon 2 (2014) is the sequel to the computer-animated action-fantasy How to Train Your Dragon (2010) that has represented the failure of the male protagonist, a young Viking teenager named Hiccup, to become a dragon fighter and his success in getting the Vikings and the dragons to live in harmony. The sequel features Hiccup as a young adult who accidentally meets his long-lost mother, Valka, who helps him in his battle against the villain, Drago Bludvist. Eventually, Hiccup and his dragon, Toothless, defeat the evil Drago Bludvist. 
- Big Hero 6 (2014) is a computer-animated superhero film that represents the adventure of the male protagonist, Hiro Hamada, a young robotics prodigy who forms a team of his science geek friends to capture the masked villain who has caused the death of his elder brother. They eventually succeed and become the city's mysterious superheroes.

\subsection{Procedure}

Data analysis was conducted in three phases. The first phase involved dividing each film into scenes and key frames that primarily depict the male protagonists' represented processes and participants' roles (Kress \& van Leeuwen, 2006). By protagonists I mean the central male characters that are involved in the creation and development of actions in the plot, i.e., the heroes, Gru in Despicable Me2, Hiro in Big Hero 6, and Hiccup in How to Train your Dragon2. The second phase involved categorizing the key frames of each animated film based on the types of processes, i.e., action processes and reaction processes, and the participants' roles occupied by the male leading characters, i.e., Actor, Goal, Reactor, and Phenomenon. Visual analysis is confined to the depiction of such leading male characters in relation to visual processes and participants' roles. In the third phase, I enlist the different types of processes and participants' roles found through analysis and examine to what extent these findings offer (non-) stereotypical depictions of male gender roles and characteristics in the selected animated films.

\section{Analytical framework}

For the purpose of visual analysis of the male protagonist's gender representation in the selected films, Kress and van Leeuwen's (2006) social semiotic multimodal model was applied. Selected key frames were examined in the light of the Representational dimension. As Kress and van Leeuwen stipulated, the Representational dimension depicts aspects of the experiential world. That is human experience of the world is represented in one of two forms; narrative or conceptual. Narrative representations involve participants who are engaged in processes under particular circumstances. Different types of processes can be visually realized. Action process is demonstrated through the presence of a vector that connects participants, i.e., Actor and Goal. In this case, the process is called "transactional" (2006, p.50). Vector is realized in the form of a line, usually diagonal, that departs from an Actor and is directed at a Goal, e.g. stretched limb, or a road. Other action processes do not involve a Goal; these are called "non-transactional" (p.63), as in the case of metrological maps. A third type represents "Events" (p.64) which depict a vector directed at Goal whereas 
the Actor is kept anonymous or deleted from the represented action. Finally, action processes can be either unidirectional between an Actor and a Goal, or bidirectional between two active participants, i.e., "Interactors" (p.66). Reaction processes involve an eye line between a Reactor and a Phenomenon. In such processes, reactors are humans who are capable of observing and reacting to phenomena deploying facial expressions.

Three more types of processes are verbal, mental, and conversion. Verbal and mental processes are illustrated in dialogue balloons and thought bubbles that are connected to participants in comic strips. Conversion processes, on the other hand, can be illustrated by diagrams that represent chain connections where participants, i.e., Relays, are Actors and Goals at the same time. However, these are not pertinent to my study. In addition, crucial to narrative representation is circumstances (Kress \& van Leeuwen, 2006). This includes the setting of the processes, i.e., "Locative circumstance", and means used to carry out processes, i.e., "Circumstance of Means" (2006, p. 72). The contrast between foregrounding and backgrounding participants and setting significantly affects the meaning constructed in the visual design and can be achieved in a range of various forms and structures (Kress \& van Leeuwen, 2006).

Applying Kress and Van Leeuwen's (2006) model, I analyze the three male protagonists' represented processes and participant roles which contribute to their visual portrayal as male figures. A number of significant concluding remarks were reached about the protagonists' physical capacities and characteristic qualities, which jointly construct their gender identities. Selected key frames that illustrate the visual aspects under study are provided in the Appendices (pp.21-25). Each male protagonist has a separate appendix that is entitled by his name and the film title.

\section{Analysis and findings}

This section is devoted to presenting the findings of the visual analysis of the three male protagonists' depiction, namely Gru in Despicable Me II, Hiro in Big Hero 6 and Hiccup in How to Train your Dragon II. Analysis focused on the key frames that picture each male protagonist involved in various represented narrative processes. Types of represented processes, namely Action and Reaction processes, and the protagonists' participant roles, i.e., Actor, Goal, Reactor or Phenomenon, are identified in relation to male identities construction.

\subsection{Visual representation of Gru in Despicable Me II}

In Despicable Me II, Gru is portrayed as an anti-villain hero whose experience as a former super-villain enables him to cooperate with the Anti-Villain League 
(AVL) to catch the villain Al Macho. Gru is also rendered as a single adoptive father of three little girls and a spouse of Lucy, his business partner at the AVL. Gru's visual representation as a male protagonist through narrative processes and participant roles indicate his personal qualities and physical capacities as a hero, father and spouse. He is rendered with a mixture of personal features including care towards family, bravery, heterosexuality; attitudes and behaviors such as aggression, use of weapons; and physical capacities namely vulnerability and defenselessness.

A characteristic feature of Gru's portrayal as a male lead is his commitment and care towards his three adopted daughters, Margo, Edith and Agnes. He mainly occupies the participant role of Actor in different transactional action processes that represent how much he cares about his daughters and acts responsibly towards them. As depicted in several Frames (Appendix I, pp. 2123), he performs some preparation for Agnes' birthday party. He blows a large unicorn balloon (Frame G1), grills meat and chicken for the guests (Frame G2), and dresses up like a fairy princess to perform for his little daughter (Frame G3). He is also pictured in Frame G4 carrying his little sleeping daughter on his shoulder to put her to bed. These examples of transactional action processes portray Gru as a caring and devoted parent.

Despite this kind part of Gru's characterization, his behavior is frequently associated with aggression and hostility. Such negative behaviors are revealed through several transactional action processes carried out by Gru. In Frame G5, for instance, he soaks Jillian, an annoying female acquaintance of his, with water using a water hose. The frame depicts Gru directing the water hose at Jillian's face and forcefully splashing water that forms a vector directed at her face; this is both violent and humiliating. Another depiction of Gru's hostility is illustrated in Frame G6 which represents his first encounter with agent Lucy. The frame pictures Gru trying to evade speaking with Lucy by attacking her using his freeze gun, one of his most effective weapons. In these two examples, he appears in the participant role of Actor performing different transactional action processes that involve other characters as Goals. Gru also uses violence as means of expressing anger as shown in Frame G7. He is depicted furious because he fails to ask Lucy out on a date; so he aims his fire gun at the phone placed on his desk and burns it. Such action processes portray Gru as an aggressive man who frequently resorts to violence which is a distinct feature of his male character.

Very much relevant to Gru's aggression is his heavy reliance on various weapons. Several transactional action processes involve Gru using untraditional types of weapons. Besides using his freeze gun as indicated in Frame G6 and fire gun as shown in Frame G7, he appears holding two large guns, in Frame G8, 
which he uses to fight evil minions that have been captured by the villain Al Macho. These examples of action processes reflect Gru's skills in using various types of weapons for multiple purposes. On top of that, bravery is a key personal quality of Gru's character. He is portrayed as a brave hero through a number of transactional action processes. For example, Frame G9 illustrates how Gru courageously rescues his partner Lucy who is tightly tied up with explosive rockets to the back of a shark and eventually defeats evil, i.e., the villain Al Macho, as indicated in Frame G10. These action processes suggest bravery as a characteristic trait of Gru's identity in this film.

Furthermore, a significant feature of Gru's portrayal as a male lead is heterosexuality. This feature is indicated in certain action processes including getting married, kissing and being kissed. He occupies the role of Goal receiving kisses form Lucy as depicted in Frame G11 and he appears as Actor kissing his spouse Lucy as shown in Frame G12 on their wedding day which is pictured in Frame G13. In fact, such action processes reflect Gur's romantic and heterosexual interest in having a female partner as a wife which establishes his andocentric hetero-normative identity.

Although Gru is portrayed as an aggressive and brave man, on several occasions he seems to lack physical strength and the capacity to protect himself against sudden attacks. In numerous action processes, Gru occasionally appears as a Goal in some action processes which suggests his susceptibility to attacks and defenselessness. As pictured in Frame G14, for instance, he is accidentally hit by two minions using a large mace. Also, Frame G15 depicts how he is attacked by Lucy using her lipstick taser. Furthermore, during a blind date, as in Frame G16, he appears as the Goal of his date's hand grip that attempts to take his wig off intending to expose him in public. Frame G17 depicts him attacked by a chicken during his breaking and entry of Al-Macho's restaurant. In addition, as revealed in Frame G18 he gets burnt with fire and is shot with sharp needles in the face during his attempt to cross El Macho's secret entrance. These multiple action processes represent Gru's moments of weakness where he fails to defend himself against unexpected attacks. However, these processes indicate his endurance of multiple forms of physical pain as he constantly resumes his mission after each physical attack. This represents a crucial quality of Gru's male identity.

Moments of Gru's weakness and vulnerability are also indicated through reaction processes which involve him as a phenomenon. For example, Frame G22 depicts him on the floor watched by others as he experiences physical pain and weakness. Frames G23 and G24 represent similar reaction processes which render Gru as a Phenomenon observed by other characters, including his 
minions, Lucy and his daughters, for his vulnerability. Finally, vulnerability is also indicated through expressions of fear and anxiety through reaction processes that picture Gru as a Reactor. This is illustrated in Frame G19 as he reacts with fear while watching a video of a transformed monster in the AVL. Also, in Frame G20, he appears intimidated by his phone due to his failure to call agent Lucy to ask her out on a date. In addition, Frame G21 displays Gru's looks of fear as he hangs by a falling metal construction during his confrontation with the villain Al Macho. In these reaction processes, Gru plays the role of Reactor indicating his feelings of fear and anxiety, which contribute to the depiction of his vulnerability and defeat.

Such visual representation indicates few non-traditional traits besides maintaining several stereotypical masculine traits of the male lead. Gru's male identity is constructed as a caring parent, brave hero who is skilled in using weapons, heterosexual spouse, aggressive yet occasionally vulnerable and defenseless. These features represent a mixture of qualities that deviate from the stereotypical masculine portrayal of animated protagonists. Therefore, Gru's visual rendering seems more credible for representing a male hero who can experience setbacks as well as triumphs.

\subsection{Visual representation of Hiro in Big Hero 6}

Like Gru, Hiro Hamada fights a villain and defeats him with the help of his team of superheroes. His visual representation as a male hero through multiple narrative transactional action and reaction processes reveals his character traits and physical capacities. Hiro is portrayed as competitive, reckless, adventurous, brave, ingenious, supportive, and physically vulnerable. The first characteristic trait of Hiro's male identity is his competitiveness.

A key feature of Hiro's characterization is competitiveness. As a teenager male, Hiro's passion about designing robots and participating in robot fighting competitions is evident from the beginning of the film. This is illustrated in Frame Hir1(Appendix II, pp. 23-24) which depicts Hiro sitting down with an aggressive look on his face and holding the control unit of his robot to start the fighting game which he eventually wins as displayed in Frame Hir2. These two frames portray Hiro as an in two transactional action processes that indicate his strong desire to prove his superiority through wining robot fights using a robot of his own design. Another significant quality of Hiro's personality is recklessness. He is portrayed as an irresponsible young gambler whose interest in the science of robotics is abused and wasted through taking part in illegal robot fights and gambling. This negative quality is highlighted through depictions of the consequences of his participation in such an illegal activity. As rendered in 
Frame Hir3, he is attacked by his opponent, Yama, who wants to avenge his loss of money at the robot fight. Hiro's gambling at the robot fight also gets him detained by the police forces as displayed in Frame Hir5. In both frames, Hiro is portrayed as Goal in transactional action processes indicating his lack of care about the risky consequences of his irresponsible actions. Therefore, competitiveness and recklessness represent two major traits that characterize Hiro's behavior as a male protagonist.

Closely connected to recklessness is Hiro's spirit of adventure. His adventurous and exploratory character is reflected through several transactional action processes. Frames Hir17-19 illustrate his adventurous test of Baymax's newly developed armor suit. In these frames, Hiro tests Baymax's flying options, so he appears flying with Baymax inside a train tunnel as depicted in Frame Hir16, flying between power turbines hanging in the sky as pictured in Frame Hir17 and flying over skyscrapers and the ocean as shown in Frame Hir18. These examples of action processes represent Hiro as a risk-taker and bold male character. His daring actions reflect a key side of his male identity. His willingness to take risks also indicates his bravery while facing danger. This is depicted through his daring confrontation with the masked villain. As displayed in Frame Hir19, for instance, Hiro appears on the back of Baymax flying in the air pointing his invincible fist towards the villain Callaghan and stopping him from destroying the city. In addition, Frame Hir20 represents another example of Hiro's bravery as he appears rescuing Callaghan's daughter who has been trapped in hyper-sleep for a long time. These two transactional processes render Hiro as a brave and altruistic hero which contributes to the portrayal of his male identity.

Furthermore, ingenuity is considered a characteristic quality of Hiro's characterization. Through several transactional action processes, Hiro appears as an Actor who carries out technology-related tasks and pioneering inventions. This is illustrated by Frame Hir8 which displays his presentation of the new invention of micro-robots in front of a huge audience of scientists and professors. Moreover, Frames Hir 9-11 represent his several attempts to develop the performance options of his robot, Baymax. He scans him using a laser scanner to design his protective armor suit (in Frame Hir9); puts on the first developed armor suit (in Frame Hir10); and puts on the second armor suit which gives Baymax more super powers (Frame Hir11). Hiro is also depicted using technology constantly. Frames Hir 12-13 portray how he uses an advanced computer key-board and interactive touch screen to design different weapons for his team members to combat the masked villain. All these transactional action processes render Hiro as an ingenious prodigy which is a key feature of his male 
identity. Hiro's sophisticated mental skills are also indicated through reaction processes that depict him as a Phenomenon observed by other characters. Frame Hir8, for instance, displays how the audience of scientists, professors, family and friends watch his outstanding presentation and acknowledge his innovative potential. Similarly, Frame Hir13 represents how Hiro's creative designing skills are closely observed and highly appreciated by his team members surrounding him. Both examples of reaction processes contribute to Hiro's portrayal as an ingenious male prodigy.

As a team leader, Hiro is also characterized by being supportive of his team members. It has been pointed out above, and illustrated in Frame Hir14, that he helps his team members design and develop advanced technological weapons to combat the masked villain. On top of that, he is depicted helping each member of his team test their new weapons. In Frame Hir14 he appears assisting GoGo to stand up after falling as she tests her new speed wheels. Also, in Frame Hir15 he stands next to Wasabi cheering him as he tests his laser-hand-weapons. These examples of transactional action processes contribute to the depiction of Hiro as a helpful and cooperative leader.

In addition to Hiro's several personal traits, he is rendered as a physically vulnerable male figure. In some action processes, he occupies the role of Goal and appears susceptible to others' physical attacks. For example, in Frame Hir3, Hiro is attacked and his robot is taken from him by his hostile opponent, Yama. In this frame, Hiro appears physically incapable of defending himself which in turn renders him as physically vulnerable. Similarly, during his confrontation with the masked villain, he is fiercely attacked and he is detached from Baymax. As depicted in Frame Hir21, Hiro is rendered hanging helplessly upside down by a metal construction piece and incapable of rescuing himself from falling. On several occasions, he depends on other characters' protection. As illustrated in Frame Hir4, Hiro is rescued by his brother Tadashi from Yama's attack after losing the robot fight. Hiro is also rescued by Baymax repeatedly. Frame Hir6 reveals how Hiro is caught by Baymax to protect him from a fatal fall off a window during their escape from the masked villain. Also, Frame Hir7 depicts Hiro and his entire team rescued by Baymax after the masked villain has destroyed their car in the ocean. It is indicated through these examples of action processes and Hiro's participant role as Goal that he lacks physical strength and therefore, requires others' assistance and protection. Such characterization renders him as defenseless and dependent.

A final key feature in Hiro's character portrayal is his expression of emotions, particularly sadness and love. This feature is basically revealed through few action processes. In Frame Hir22, for instance, Hiro appears grieving for his late 
brother, Tadashi; he is depicted crying after having watched a video recording of Tadashi viewed by Baymax. Another occasion depicting Hiro shedding tears is the moment of leaving Baymax inside a destructive time transmitter in order to rescue himself and Callaghan's trapped daughter. Frame Hir23 represents Hiro hugging Baymax closely and crying bitterly about abandoning Baymax which would lead to its destruction. Eventually, Hiro manages to rebuild Baymax in the same design and programming which indicates his emotional attachment towards Baymax not as a robot but as a close friend. Frame Hir24 pictures a warm hug between Hiro and the newly built Baymax that manifests their strong bond. These few action processes contribute to the portrayal of Hiro as an ordinary human who sheds tears for the loss of loved ones and values relationships even with robotic devices.

Accordingly, Hiro's visual representation offers many stereotypically masculine features in addition to few traits that deviate from the stereotype of male heroes. As a team leader and a superhero, Hiro is depicted as competitive, adventurous, brave and ingenious. He is eager to win and willing to take risks. He invents unconventional weapons and combats evil courageously. These features reinforce the traditional portrayal of male (super-) heroes in animation. However, being supportive and vulnerable, expressing fear and shedding tears deviate from the stereotypical portrayal of males in animated films. Inclusion of these traits in Hiro's visual depiction offers a credible representation of a male hero that demonstrates both strengths and weaknesses.

\subsection{Visual representation of Hiccup in How to Train Your Dragon II}

Like Hiro, Hiccup is portrayed as a young intelligent hero with certain extraordinary skills. In How to Train Your Dragon II, Hiccup is portrayed as the heroic son of the great Viking Chief Stoick and he successfully avenges Stoick's tragic death and defeats the villain Drago Bludvist. Hiccup does not only lead his group of friends, including his fiancée Astrid, to combat Drago, he also leads the entire Viking island of Berk as a successor to his late father. His personal traits, behavioral attitudes and physical capacities are visually depicted through several action and reaction processes. His male identity is characterized by being adventurous, brave, skilled in using unconventional weapons, physically vulnerable and heterosexual.

First, Hiccup's sense of adventure is indicated visually through multiple action processes. Some action processes involve Hiccup testing new and risky flying moves and positions with his dragon, Toothless, one of the most dangerous and fiercest dragons known at the time. These can be illustrated by Frame Hic1 (Appendix III, pp. 24-25) which pictures him riding and flying with 
Toothless in an upside down position. Also, in Frame Hic2, Hiccup is depicted flying independently with his flying wing suit. However, Toothless maintains Hiccup's stability in the air through blowing fire from its mouth under him. These instances of transactional action processes render Hiccup as an adventurous and skillful dragon rider. Hiccup also exhibits interest in exploring new lands and adding them to his hand-drawn map. Frame Hic3, for instance, represents how Hiccup updates his map by drawing the new areas that he has discovered. Also, Frame Hic4 depicts him riding on Toothless' back and flying across a dark forest in one of his exploratory expeditions of new lands. These examples of transactional action processes contribute to Hiccup's portrayal as an adventurous dragon rider and a curious explorer.

Another major traits of Hiccup's character as the male lead is his bravery. This distinctive quality is represented through different transactional action processes in which he appears as an Actor. In fact, Hiccup's adventurous flying practice and exploratory expeditions demonstrate his daring male character. His bravery is also exhibited through his confrontation with the villain Drago and his evil alpha dragon. Frame Hic5 illustrates how Hiccup challenges Drago who has kidnapped Toothless and manages to free it from the evil control of the villain. These examples of transactional action processes render Hiccup as a brave and victorious leader. Moreover, Hiccup's bravery is clearly demonstrated through his constant contact with dragons. For example, he manages to face, influence and control any dragon. Frame Hic6 illustrates how Hiccup approaches a large dragon fearlessly without any use of weapons. Similarly, Frame Hic7 depicts him riding one of the small dragons for the first time skillfully and courageously. These various examples of transactional action processes represent Hiccup's bravery and dragon-related skills as two distinctive features of his male identity.

Besides his bravery, Hiccup is portrayed as a non-violent warrior. Throughout the whole film, he does not engage in physical fights or aggressions. On repeated occasions, he uses different innovative weapons to scare enemies away, but not to kill or even cause any physical injuries. This is illustrated during his first encounter with the dragon trappers who attack him and his fiancée Astrid. As depicted in Frame Hic8, instead of fighting them, Hiccup waves his fire sword to scare them away. In Frame Hic9, he prevents Astrid from fighting them. These two instances represent two transactional processes which render Hiccup as a non-violent male character. Furthermore, Hiccup's non-aggressive attitude is demonstrated during his several encounters with the villain Drago. In all such encounters, Hiccup does not resort to physical violence but mainly adopts a defensive stance. In Frame Hic10, for instance, he seems to prevent Toothless 
from attacking Drago using an extended arm as a gesture of non-aggressive intentions.

Also, in their final confrontation, Hiccup relies on his different weapons to impede Drago's aggression without attempting to kill or physically harm him. As pictured in Frame Hic11, he sprays green gas using his flammable gas device to distract Drago and scare him. Similarly, in Frame Hic12, he uses his fire sword to prevent Drago from grapping his weapon and fighting back. These action processes depict how Hiccup maintains a defensive position against the aggressive assaults of the villain Drago. Eventually, complete victory is achieved by Toothless, not Hiccup. Frame Hic13 displays Hiccup and his mother Valka passively witnessing Toothless' triumph over the evil alpha dragon. In this instance, Hiccup occupies the role of passive Reactor in a reaction process that contributes to his portrayal as a non-violent hero. In fact, these action and reaction processes represent Hiccup's non-aggressive behavior and skills of using several unconventional weapons, which reflects key feature of his portrayal as a male leader and warrior.

Despite Hiccup's heroic portrayal, he demonstrates some weaknesses. Hiccup seems physically vulnerable and incapable of protecting himself. As Frame Hic 14 displays Hiccup appears to have a thin and small body in addition to a handicap, i.e. amputated foot. Such physical construction renders Hiccup susceptible to others' attacks. Through some action processes, Hiccup appears as a Goal that is incapable of defending himself and ceasing others' assaults. Frame Hic15 exemplifies how he is attacked by Toothless under the evil influence of the villain Drago. He is rendered helpless and incapable of protecting himself. On other occasions, he appears dependent on others, particularly Toothless, for protection. This can be represented in Frame Hic16 where Toothless protects Hiccup with his invincible dragon body and covers him with his wings. These instances portray Hiccup as a physically defenseless male figure who needs others' protection.

Finally, Hiccup's male identity is characterized by heterosexuality. He is established as a heterosexual male who loves his fiancée. This feature is indicated through his multiple action processes that depict him as a Goal of Astrid's kisses or as an Actor initiating kisses with her as illustrated in Frames Hic17-18 respectively. Hiccup's visual representation offers many stereotypically masculine features in addition to few traits that deviate from the stereotype of male heroes. As a heroic leader, Hiccup is depicted as adventurous, brave, skilled in using weapons and with heterosexual interests. These features reinforce the traditional portrayal of male heroes in animation. However, being physically vulnerable and handicapped deviates from the stereotypical portrayal 
of males in animated films. Such visual depiction offers some development in the representation of males and masculinity in this animated film.

\section{Discussion}

This study has attempted to examine the representation of male protagonists in the three selected animation films through analysis of the representational dimension of their visual depiction, namely the narrative representation of processes and participant roles. It is evident that each male lead seems to maintain several stereotypical features of masculinity (Schmitt et al., 2008). However, the three protagonists represent a slight progress in the portrayal of males in the selected animated films. Regarding stereotypical traits, the three male leads, Gru, Hiro and Hiccup, demonstrate bravery, ingenuity, leadership, skills in using weapons and a sense of adventure. However, two of the three males, Gru and Hiccup, are portrayed as heterosexual, which is a stereotypical masculine feature (Bereska 2003; Towbin et al. 2008) and only one protagonist, Gru, displays the stereotypical aggressive behavior of masculinity (Schmitt et al, 2008). On the other hand, the three protagonists deviate from the stereotypical image of male bravado by indicating non-stereotypical features including expression of fear and intimidation, supportiveness and physical handicap. In fact, all three males are rendered physically vulnerable and incapable of protecting themselves; therefore, they exhibit dependency on others for assistance and protection. This infusion of traditional and untraditional features offers a realistic and complex depiction of a brave and heroic male protagonist who may experience temporary failures and defeats at certain moments in his journey.

These findings contradict findings of past studies on the analysis of stereotypical representations of males and masculinity in early animation productions (Bazzini et al., 2010; Coyne et al., 2016; Wiersma, 2000). However, they confirm the findings of previous research on gender portrayal of males in recently produced film animations (Patterson \& Spencer, 2017; Putri, 2017). In fact, all three male protagonists are visually depicted as "new men" or "Beta males" (Gillam \& Wooden, 2008) rather than as stereotypical Alpha males. This is evident in Gru's intimidation and defenselessness, Hiro's supportiveness and emotional-orientation, and Hiccup's non-aggression and physical handicap. These personal features and traits deviate from the masculine stereotype that had been presented in animation production. The three protagonists combine seemingly contradictory traits; however, this infusion enriches their characterization and makes it credible and realistic (Putri, 2017). Gru demonstrates aggression and intimidation, Hiro exhibits competitiveness and 
supportiveness and Hiccup appears adventurous despite his physical incapacity. Finally for all three males, they are rendered dependent on others' despite their bravery and assertiveness. This breaks the stereotypical portrayal of male heroes as muscular and physically powerful (Baker \& Raney, 2007; Coyne, et al., 2014; England et al., 2011). Nonetheless, the observed progress in the rendering of males should be a continuous effort.

Such rich and multifaceted representations of male protagonists have significant implications for viewers, animated film producers and discourse analysts. For viewers, families are alerted about the negative impact of the animation production that reinforces stereotypical images of gender values and behavior in children's mind. Consequently, parental guidance and selection are required to limit children's exposure to gender stereotypes and misconceptions in animated films. Moreover, parents need to socialize their children towards androgyny, i.e., eliminate or minimize teachings and expectations of stereotypical femininity and masculinity. Androgynous parents can offer their children a wider range of possible behaviors and attitudes (Lindsey, 2016). Concerning animated film makers, they can benefit from the present findings in promoting more balanced, realistic and unprejudiced portrayals of male roles in order to resist stereotypical perceptions and expectations. Lindsey (2016) stated that "gender should liberate rather than constrain" people's behaviors and experiences (p. 89). Therefore, conceptions of femininity and masculinity need to change toward gender role flexibility which can explain how feminine and masculine traits are changeable. In fact, the concept of androgyny refers to the integration of feminine and masculine traits. Unfortunately, media representations of androgyny are stereotyped. They associate this concept more with femininity than masculinity. Such representation negatively stereotypes the "androgynous man" portraying him as feminine, i.e., weak and ineffectual (Lindsey, 2016, p. 89). For that, animation writers and producers should embrace more balanced androgynous models of males as well as females. Finally, the present study offers an application of the visual discourse analysis that can benefit analysts and students of linguistic discourse analysts and media.

\section{Conclusion}

As Giroux (1999) argued means of entertainment, including animated films, have strong educational impact. They influence viewers' cultural values and social roles and ideals. Brydon (2009) and Gillam and Wooden (2008), among other scholars, have called for more realistic understandings and representations of masculinity in children's animated films. As socializing agents, Lugo-Lugo and Bloodsworth-Lugo (2009) argued that animated films guide children through critical concepts such as race, gender and sexual orientation, which are 
not innocently represented as the early analysts claimed (Bell, Haas, \& Sells, 1995). These films reinforce "normalized racial and sexual" scenarios and expectations (Lugo-Lugo \& Bloodsworth-Lugo, 2009, p.168). Given that these films are intended for global audiences, they can spread their toxic messages and prejudices worldwide implicitly and effectively.

The provided visual analysis of the representational dimension focusing on represented narrative processes and participant roles have yielded significant remarks about the three male protagonists' characteristic traits and physical capacities that contribute to the construction of their gender identities and roles in the selected animated films. Since examining the content, visual, verbal and/or thematic, of animated films is regarded as an essential and logical step towards investigating their impact on viewers (Martin \& Kazyak, 2009), my study has fulfilled this purpose. Enormous numbers of viewers watch animation films repeatedly in movie theatres, DVD releases, on television and even through means of modern online social media. Therefore, they offer significant and rich data for analysis and investigation.

The scope of my findings has been confined to revealing the depiction of the three male protagonists in the selected animated films. Therefore, findings cannot be generalized to represent male depictions in the animated films medium. However, future research can broaden the scope of analysis to encompass a larger corpus of animated films and compare gender representation of female and male characters. Also, analysts can apply other dimensions of Kress and van Leeuwen's (2006) model or other visual analytical models that pay further attention to compositional dimensions of visual imaging which can contribute to and deepen the understanding of gender roles representations of in animations.

\section{References}

Ahmed, S., \&Abdul Wahab, J. (2014). Animation and socialization process: Gender role portrayal on cartoon network. Asian Social Science, 10 (3), 44-53.

Baker, K., \& Raney, A. (2007). Equally super? Gender-role stereotyping of superheroes in children's animated programs. Mass Communication and Society, 10(1), 25-41.

Baranova, Y. (2014). The role of animation in spiritual and moral development of preschool children. Koncept : Scientific and Methodological e-magazine,11, 6-11.

Barnes, K. (2012). Perceptions of gender in young consumers of animated films. (Master's thesis, University of Louisville, Louisville, Kentucky, United Stated of America). Retrieved from https://doi.org/10.18297/etd/72 
Bazzini, D., Curtin, L., Joslin, S., Regan, S., \& Martz, D. (2010). Do animated Disney characters portray and promote the beauty-goodness stereotype? Journal of Applied Social Psychology, 40(10), 2687-2709.

Bell, E., Haas, L., \& Sells, L. (1995). Introduction: Walt's in the Movies. In E. Bell, L. Haas \& L. Sells (Eds). From Mouse to Mermaid: The Politics of Film, Gender, and Culture (pp. 1-17). Bloomington: Indiana UP

Bem, S. L. (1974). The measurement of psychological androgyny. Journal of Consulting and Clinical Psychology, 42(2), 155162. https://doi.org/10.1037/h0036215

Bereska, T. (2003).The changing boys' world in the 20th century: Reality and "fiction". Journal of Men's Studies, 11(2), 157-74.

Birthisel, J. (2014). How body, heterosexuality and patriarchal entanglements mark non-Human characters as male in CGI-animated children's films. Journal of Children and Media, 8(4), 336-52.

Box Office Mojo. (2019). Retrieved from https://www.boxofficemojo.com/genres/chart/?id=animation.htm on 10 Oct, 2019.

Breaux,R. (2010). After 75 years of magic: Disney answers its critics, rewrites African American history, and cashes in on its racist past. Journal of African American Studies, 14(4), 398-416.

Bruce, A. (2007). The role of the "Princess" in Walt Disney's animated films: Reactions of college students. Studies in Popular Culture, 30 (1),1-25.

Brydon, S. (2009).Men at the heart of mothering: Finding mother in Finding Nemo. Journal of Gender Studies, 18(2), 131-46.

Bussey, K., \& Bandura, A. (1999). Social cognitive theory of gender development and differentiation. Psychological Review, 106(4), 676-713.

Carrigan, T., Connell, B.\& Lee, J. (1985). Towards a new sociology of masculinity. Theory and society, 14(5), 551-604.

Coffin, P., \& Renaud, C. (Directors). (2013). Despicable Me 2. [Motion picture]. USA: Universal Pictures, Illumination Entertainment.

Condry, J. (1984). Gender identity and social competence. Sex Roles, 11(5-6), 485-511. Connell, R.W. (2005) Masculinities. Cambridge: Polity Press.

Coye, S., \& Whitehead, E. (2008). Indirect aggression in animated Disney films. Journal of communication, 58(2), 382-395.

Coyne, S., Linder, J., Rasmussen, E., Nelson, D., \& Collier, K. (2014). It's a bird! It's a plane! It's a gender stereotype!: Longitudinal associations between superhero viewing and gender stereotyped play. Sex Roles, 70:416-430.

Coyne, S., Lindner, J., Rasmussen, E., Nelson, D., \& Birkbeck,V. (2016). Pretty as a princess: Longitudinal effects of engagement with Disney princesses on gender stereotypes, body esteem, and prosocial behavior in children. Child Development, 87(6), 1909-1925.

Davis, A. M. (2015). Handsome heroes and vile villains. Bloomington: Indiana University Press. 
Davis, M. M. (2014). From snow to ice: A study of the progression of Disney princesses from 1937 to 2014. Film Matters, 5(2), 48-52. doi:10.1386/fm.5.2.48_1

DeBlois, D. (Director). (2014). How to train your dragon 2. [Motion Picture]. USA:DreamWorks Animation.

Decker, J.T. (2010). The portrayal of gender in the feature-length films of Pixar Animation Studios: A content analysis. (Master Thesis, Auburn University, Auburn, Alabama). Retrieved from

https:/etd.auburn.edu/bitstream/handle/10415/2100/Jonathan\%20Decker\%20Thesis\% 20Final.pdf? sequence $=2 \&$ isAllowed $=y$

Ebrahim, H. (2014). Are the "Boy" at Pixar afraid of little girls? Journal of Film and Video, 66(3), 43-56.

Elnahla, N. (2015). Aging with Disney and the gendering of evil. Journal of Literature and Art Studies, February, 5( 2), 114-127. doi: 10.17265/2159-5836/2015.02.004

England, D., Descartes, L., \& Collier-Meek, M. (2011). Gender role portrayal and the Disney princesses. Sex Roles, 64, 555-567.

Finklea, B.W. (2014). Examining masculinities in Pixar's feature films: What it means to be a boy, whether human, fish, car, or toy. (Ph.D. Dissertation, The University of Alabama, Tuscaloosa, Alabama)

Fischer, S. (2010). Powerful or pretty: A content analysis of gender images in children's animated films. (MA thesis,Auburn University, Auburn, Alabama).

Gillam, K., \& Wooden, S. R. (2008). Post-princess models of gender: the new man in Disney/Pixar. Journal of Popular Film and Television, 36 (1) 2-8.

Giroux, H. (1999). The Mouse that Roared: Disney and the End of Innocence. Laham, Md: Rowan \& Littlefield.

Giroux, H., \& Pollock, G. (2011). Are Disney movies good for your kids? In S. R. Steinberg \& J. L. Kincheloe (Eds.), Kinderculture: The corporate construction of childhood (pp. 73-92). Boulder: Westview.

Gökçearslan, A. (2010). The effect of cartoon movies on children's gender development. Procedia Social and Behavioral Sciences. 2(2), 5202-5207.

Hall, D., \& Williams, C. (Directors). (2014). Big Hero 6. [Motion picture]. USA: Walt Disney Animation Studios.

Hapkiewicz, W. (1979). Children's reactions to cartoon violence. Journal of Clinical Child Psychology, 8, 30-34.

Hayes, S., \&Tantleff-Dunn, S. (2010). Am I too fat to be a princess? Examining the effects of popular children's media on young girls' body image. British Journal of Development Psychology, 28, 413-426.

Hoffner, C. (1996). Children's wishful identification and parasocial interaction with favorite television characters. Journal of Broadcasting and Electronic Media, 40, 389-402.

Holub, S. C., Tisak, M. S., \& Mullins, D. (2008). Gender differences in children's hero attributions: Personal hero choices and evaluations of typical male and female heroes. Sex Roles, 58 , 567-578. Doi: 10.1007/s11199-007-9358-2 
Howson, R. (2008). Hegemonic masculinity in the theory of hegemony: A brief response to Christine Beasley's rethinking hegemonic masculinity in a globalizing world. Men and Masculinities, 11(1), 109-113.

Indhumathi, R. (2019). The influence of sex role perception on career aspirations and self-esteem in children with a preference for disney movies. International Journal of Indian Psychology, 7(1), 183-195. DIP:18.01.020/20190701. DOI:10.25215/0701.020

Ivanic, R. (1998). Writing and identity: The discoursal construction of identity in academic writing. Amsterdam: John Benjamins Publishing company.

Jeffords, S. (1995). The curse of masculinity: Disney's beauty and the beast. In E. Bell, L. Haas, \& L. Sells (Eds.) From mouse to mermaid: The politics of film, gender, and culture (pp. 161-172). Bloomington, IN: Indiana University Press.

Klein, H., \& Shiffman, K. (2006). Messages about physical attractiveness in animated cartoons. Body Image, 3, 353-363.

Klein, H., \& Shiffman, K. (2008). What animated cartoons tell viewers about assault? Journal of Aggression, Maltreatment \& Trauma, 16(2), 181-201.

Kress, G., \& van Leeuwan, T. (2006). Reading images: The grammar of visual design. London: Routledge.

Laemle, J. L. (2018).Trapped in the mouse house: How Disney has portrayed racism and sexism in its princess films. Student Publications, 692. Retrieved from https://cupola.gettysburg.edu/student_scholarship/692

Leaper, C., Breed, L., Hoffman, L., \& Perlman, C. (2002). Variations in the genderstereotyped content of children's television cartoons across genres. Journal of Applied Social Psychology, 32(8), 1653-1662.

Letaief, R. (2015). Stereotypes in Disney's classics: A reflection and shaping of American culture. (Master's Thesis, University of Manouba, Manouba, Tunisia). Retrieved form

https://www.academia.edu/37432261/Stereotypes_in_Disneys_Classics_A_Reflection and_Shaping_of_American_Culture

Lindsey, L.L. (2016). Gender roles: A sociological perspective. Routledge: London.

Lueke, A. I. (2014). The Disney evolution: Princesses as positive role models. (Honors Thesis, University of Dayton, Ohio, United States of America). Retrieved from https://ecommons.udayton.edu/cgi/viewcontent.cgi?article=1030\&context=uhp_the ses

Lugo-Lugo , C.R., \& Bloodsworth-Lugo, M. K. (2009). "Look out new world, here we come"? Race, racialization, and sexuality in four children's animated films by Disney, Pixar, and DreamWorks. Cultural Studies: Critical Methodologies, 9(2), 166-178.

Macaluso, M. (2018). Postfeminist masculinity: The new Disney norm? Social Sciences, 7(11), 1-10.

Martin, K. A., \& Kazyak, E. (2009). Hetero-romantic love and heterosexiness in children's G-rated film. Gender \& Society, 23(3), 315-336.

Mills, S. (1995). Feminist stylistics. London: Routledge. 
Ochs, E. (1988). Culture and language development: Language acquisition and language socialization in a Samoan village. Cambridge: Cambridge University Press.

Ochs, E., \& Schieffelin, B. (2008). Language socialization: An historical overview. In P. Duff \& N. Hornberger (Eds.), Encyclopedia of Language and Education (pp.2580-2594). New York: Springer US.

Padilla-Walker, L. M., Coyne, S. M., Fraser, A. M., \& Stockdale, L. A. (2013). Is Disney the nicest place on earth?A content analysis of prosocial behavior in animated disney films. Journal of Communication, 63, 393-412.

Patterson, G., \& Spencer, L. G. (2017). What's so funny about a snowman in a tiara? Exploring gender identity and gender nonconformity in children's animated films. Queer Studies in Media \& Popular Culture, 2(1), 73-93. Doi: 10.1386/qsmpc.2.1.73_1

Peirce, K. (1989). Sex-Role Stereotyping of Children on Television: A Content Analysis of the Roles and Attributes of Child Characters. Sociological Spectrum, 9, 321 -328.

Pimentel, O., \& Velázquez, P. (2008). Shrek 2: An appraisal of mainstream animation's influence on identity. Journal of Latinos and Education, 8 (1), 5-21.

Putri, R. T. (2017). Gender role ideology in Pixar's Wall-E and Monsters University. Kata Kita: Journal of Language, Literature, and Teaching , 5, (3), 113-120.

Schmitt, D. P., Voracek, M., Realo, A., \& Allik, J. (2008). Why can't a man be more like a woman? Sex differences in big five personality traits across 55 cultures. Journal of personality and social psychology, 94(1), 168-182. doi:10.1037/00223514.94.1.168

Seybold, S. and Rondolino, M. (2018). Conforming beasts and compliant princesses: A radical appraisal of Disney's 1990s Americana rhetoric. Visual Inquiry: Learning \& Teaching Art , 7(2), 95-110.

Slaby, R., \& Frey, K. (1975). Development of gender constancy and selective attention to same-sex models. Child Development, 46, 849-56.

Smith, S., Pieper, K., Granados, A. \& Choueiti, M. (2010). Assessing gender-related portrayals in top-grossing g-rated films. Sex Roles, 62,774-786.

Sumera, L. (2008). The mask of beauty: Masquerade theory and Disney's Beauty and the Beast. Quarterly Review of Film and Video, 26(1), 40-46,

Thompson, T., \& Zerbinos, E. (1995). Gender roles in animated cartoons: Has the picture changed in 20 years? Sex Roles, 32( 9-10), 651-673.

Thompson, T., \& Zerbinos, E. (1997). Television cartoons! Do children notice it's a boy's world? Sex Roles, 37, (5-6), 415- 432.

Tóth , Z. A. (2017) Disney's violent women in quest of a 'fully real' violent woman in American cinema, Brno Studies in English, 43 (1), 185-212.

Towbin, M. A., Haddock, S. A., Zimmerman, T. S., Lund, L. K., \& Tanner, L. R. (2003). Images of gender, race, age, and sexual orientation in Disney feature-length animated films. Journal of Feminist Family Therapy, 15, 19-44.

Ward, L. M., \& Aubrey, J. S. (2017). Watching gender: How stereotypes in movies and on TV impact kids' development. San Francisco, CA: Common Sense. 
Wiersma, B. A. (2000). The gendered world of Disney: A content analysis of gender themes in full-length animated Disney feature films (Doctoral dissertation, South Dakota State University).

Wormer, K., \& Juby, C. (2016). Cultural representations in Walt Disney films: Implications for social work education. Journal of Social Work, 16(5), 78-594. DOI: $10.1177 / 1468017315583173$

Zarranz, (2007). Diswomen strike back? The evolution of Disney's femmes in the 1990s. Atenea, 27(2), 55-65. 
Appendix I: Gru in Despicable Me II

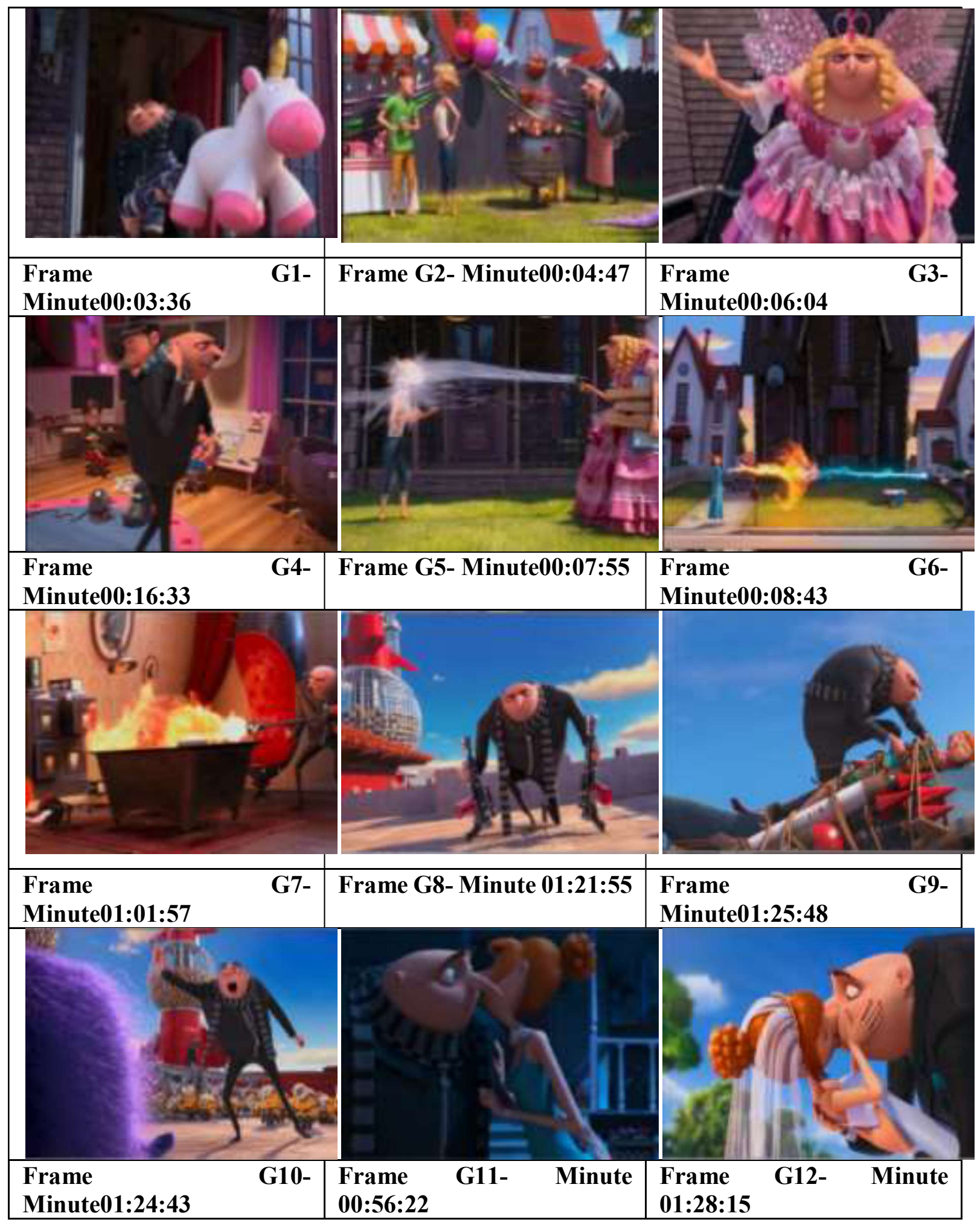




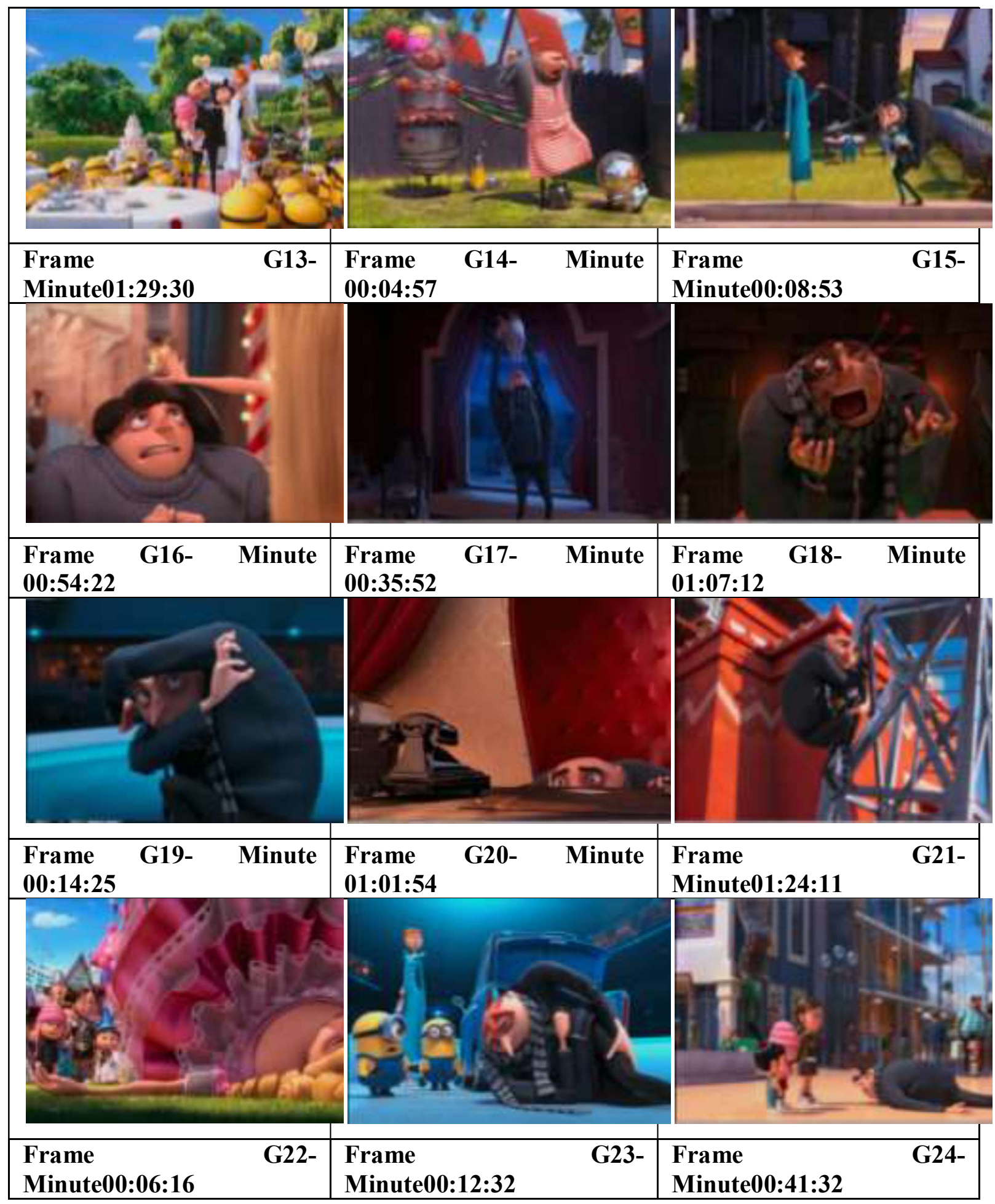


Appendix II: Hiro in Big Hero 6

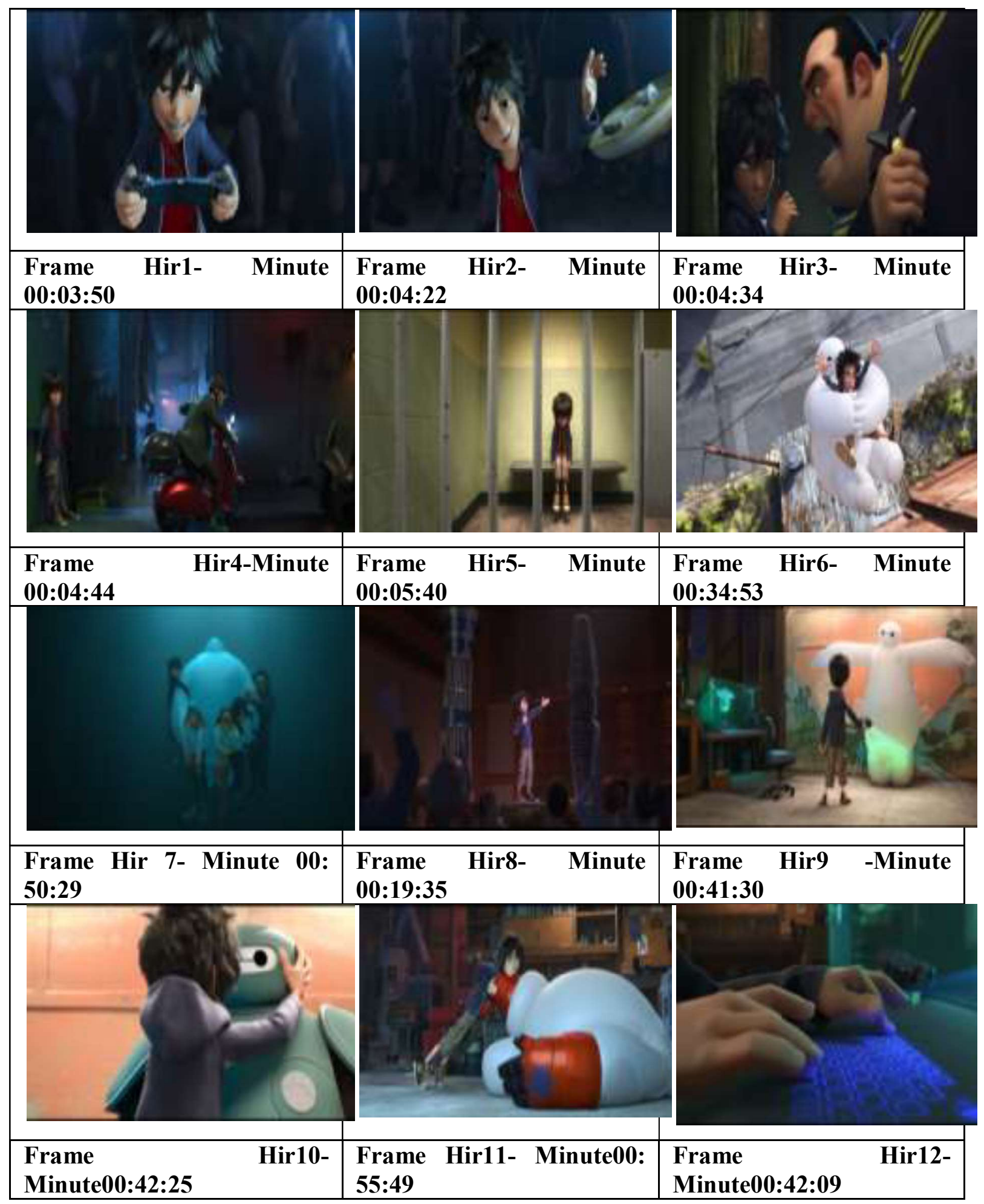




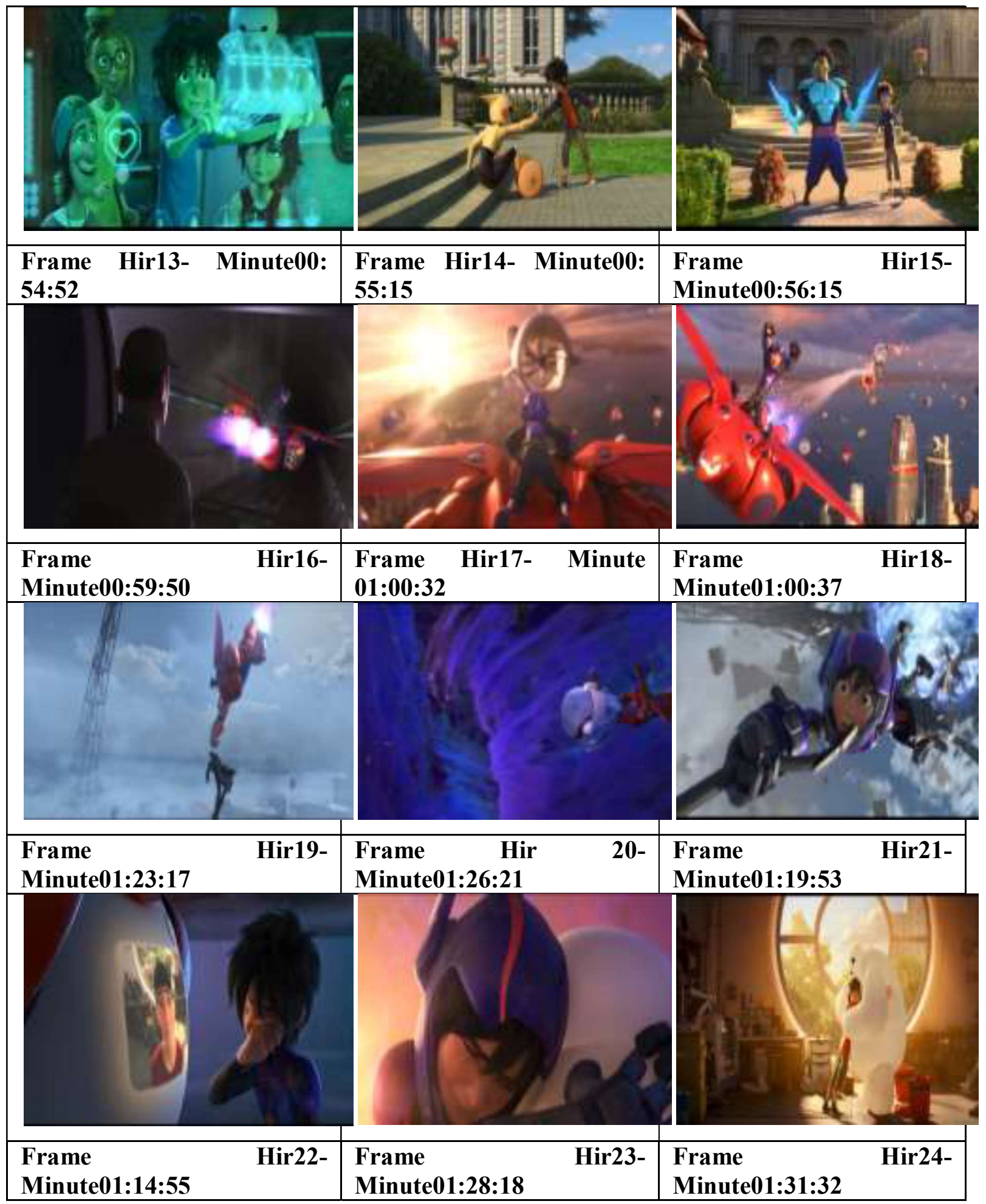


Appendix III: Hiccup in How to Train your Dragon II

\begin{tabular}{|l|l|l|l|l|l|}
\hline & & & \\
\end{tabular}




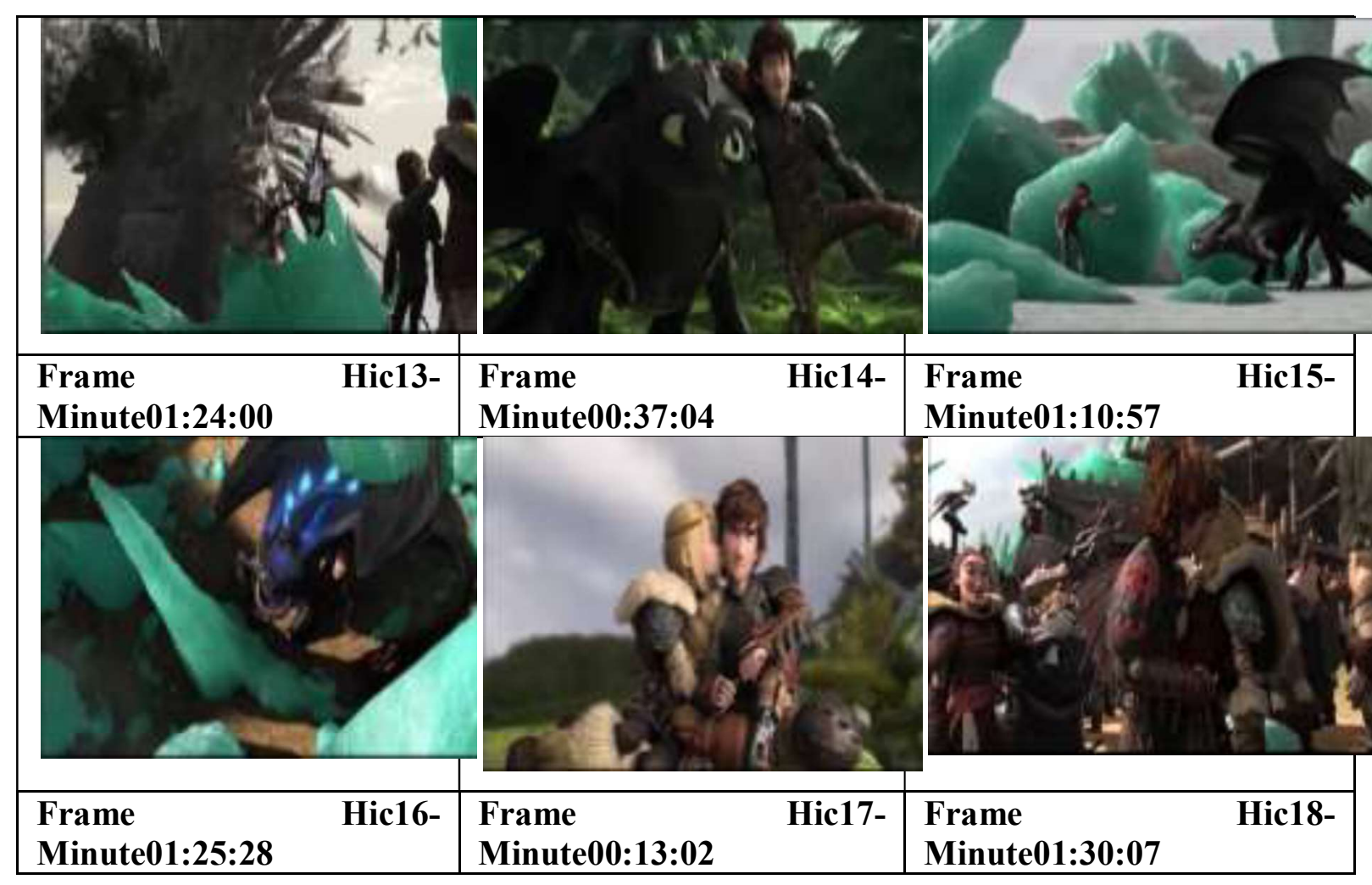

